Supporting Online Material for:

\title{
Effect of Protons on the Optical Properties of Oxide Nanostructures
}

Markus Müller, ${ }^{1}$ Slavica Stankic, ${ }^{1}$ Oliver Diwald, ${ }^{1 *}$ Erich Knözinger, ${ }^{1}$ Peter V. Sushko, ${ }^{2 *}$ Paolo E. Trevisanutto, ${ }^{2,3}$ and Alexander L. Shluger ${ }^{2}$

${ }^{1}$ Institute of Materials Chemistry, Vienna University of Technology, Veterinärplatz 1/GA, A-1210 Vienna, Austria

${ }^{2}$ Virtual Materials Laboratory, Department of Physics \& Astronomy and London Centre for Nanotechnology, University College London, Gower Street, London WC1E 6 BT, United Kingdom.

${ }^{3}$ Present address: Institute NEEL, CNRS, Grenoble, France.

*Corresponding authors: p.sushko@ucl.ac.uk, odiwald@mail.zserv.tuwien.ac.at

\section{Complete Ref. 43.}

Frisch, M. J.; Trucks, G. W.; Schlegel, H. B.; Scuseria, G. E.; Robb, M. A.; Cheeseman, J. R.; Zakrzewski, V. G.; Montgomery Jr., J. A.; Stratmann, R. E.; Burant, J. C.; Dapprich, S.; Millam, J. M.; Daniels, A. D.; Kudin, K. N.; Strain, M. C.; Farkas, O.; Tomasi, J.; Barone, V.; Cossi, M.; Cammi, R.; Mennucci, B.; Pomelli, C.; Adamo, C.; Clifford, S.; Ochterski, J.; Petersson, G. A.; Ayala, P. Y.; Cui, Q.; Morokuma, K.; Malick, D. K.; Rabuck, A. D.; Raghavachari, K.; Foresman, J. B.; Cioslowski, J.; Ortiz, J. V.; Baboul, A. G.; Stefanov, B. B.; Liu, G.; Liashenko, A.; Piskorz, P.; Komaromi, I.; Gomperts, R.; Martin, R. L.; Fox, D. J.; Keith, T.; Al-Laham, M. A.; Peng, C. Y.; Nanayakkara, A.; Gonzalez, C.; Challacombe, M.; Gill, P. M. W.; Johnson, B.; Chen, W.; Wong, M. W.; Andres, J. L.; Gonzalez, C.; Head-Gordon, M.; Replogle, E. S.; Pople, J. A. Gaussian 98, revision A.7; Gaussian, Inc., Pittsburgh PA, 1998. 


\section{(a)}

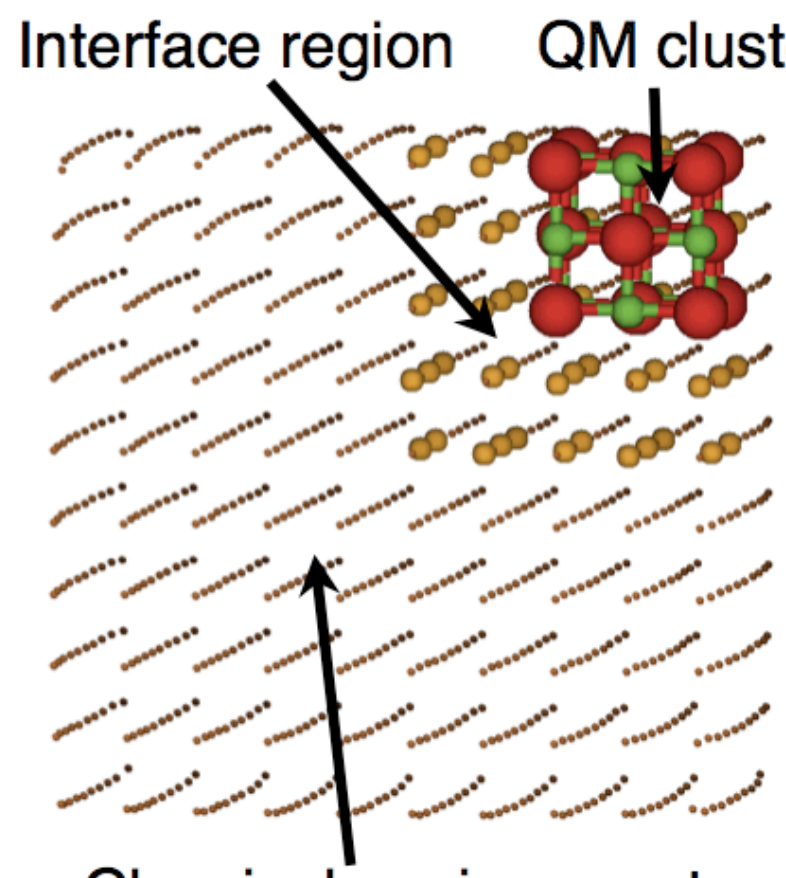

Classical environment (b)

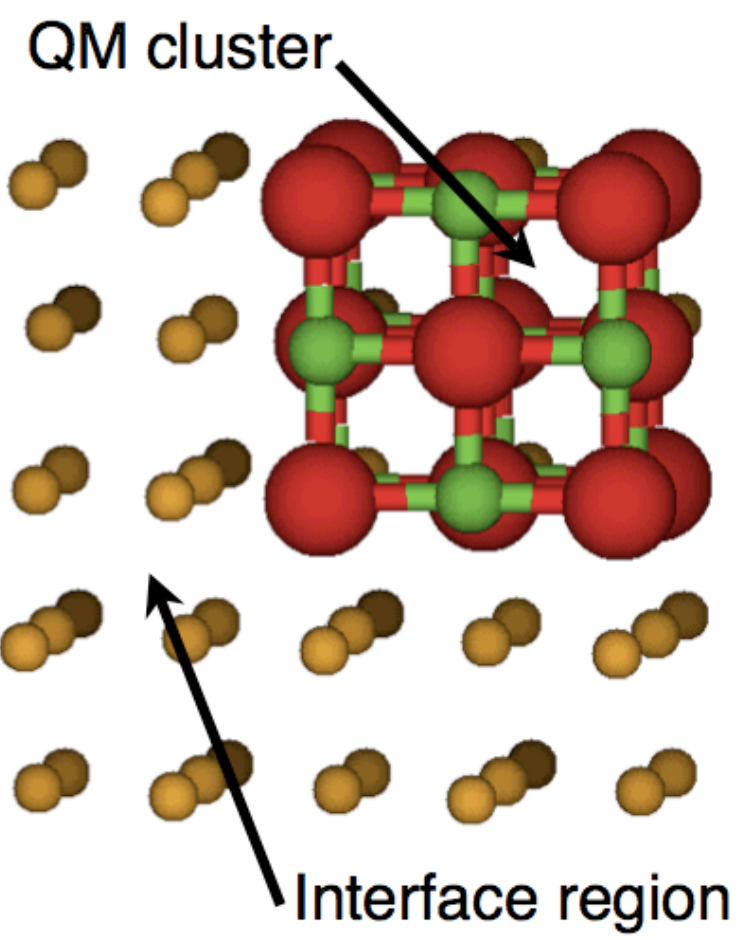

Figure 1. (a) The $10 \times 10 \times 10$ ions cube used to model an $\mathrm{MgO}$ nanoparticle. The $\mathrm{QM}$ cluster at the oxygen-terminated corner site and the interface region are explicitly shown. (b) The magnified view of the QM cluster $\left(\mathrm{Mg}_{13} \mathrm{O}_{13}\right)$ and the interface region $\left(\mathrm{Mg}^{*}{ }_{48}\right)$. Large red spheres and medium green spheres show $\mathrm{O}$ and $\mathrm{Mg}$ atoms of the QM cluster respectively. Small brown spheres show the interface $\mathrm{Mg}^{*}$ atoms. 